\title{
Peer Review Process of the Journal of the American Board of Family Medicine
}

\author{
Anne Victoria Neale, PhD, MPH, Deputy Editor, JABFM, and \\ Marjorie A. Bowman, MD, MPA, Editor in Chief, JABFM
}

With this issue, the fournal of the American Board of Family Practice officially changes its name to the Fournal of the American Board of Family Medicine. The $7 A B F M$ is a peer-reviewed journal that is indebted to the hundreds of experts who donate their time to critically appraise articles submitted for publication consideration. Peer reviewed articles are considered highly credible because they have undergone scrutiny by experts with particular knowledge in the topic. Peer review is critical in the editorial process because editors do not have the time or expertise to evaluate all aspects of each submission. The primary aims of peer review are 2-fold: to decide whether or not an article should be published (based on quality and relevance to the journal), and to improve the article before publication.

Annually, we acknowledge the individuals who support the fournal's work by serving as peer reviewers. The list of those who submitted reviews during the period of January through November 2005 is printed in this issue. We are keen to recruit new peer reviewers, and encourage interested persons to enlist by indicating their areas of expertise on our volunteer peer review form (http://www. jabfm.org/misc/PeerReviewForm.pdf).

Minorities and individuals with special interests under the primary care umbrella are especially encouraged to volunteer to participate in the $7 A B F M$ peer review process.

An overview of our procedures related to peer review and editorial decision making is described below. Each stage of our editorial process involves Rapid Review (RR), our web-based manuscript submission and management software program with particular features for authors, reviewers, and editorial and managing staff. Authors submit manuscripts for publication consideration via the RR portal on the $7 A B F M$ home page (www.jabfm. org). Journal staff assigns new submissions to a primary editor based on the article type; however, editors occasionally transfer responsibility for a manuscript to one another.

\section{Internal Peer Review Process}

All submissions first go through an internal peer review process, and most go through an external peer review process. Each submission is reviewed by the assigned editor who makes an initial decision to send the manuscript out for peer review or to reject without external review. Articles can be rejected at this stage for a variety of reasons such as similarity with a recently published article, the topic is outside of the scope of the fournal, little new information is provided, important flaws in the scientific validity, or an unprofessional presentation. If the editor believes the article may be of interest to our readers, it is then sent out for external peer review.

\section{External Peer Review Process}

The editor identifies potential reviewers seeking a balance of perspectives, such as clinical utility and rigor of the scientific methodology. We try to get 3 informative reviews for each manuscript. Several approaches may be used to find reviewers. Of course, the editorial board is frequently consulted. The RR reviewer database can be searched by name or by area of expertise and is used to identify previous reviewers who have produced high quality reviews within the requested time frame. We avoid overloading reviewers, and the RR database contains information on reviewing history, including number of current assignments, reviews completed in the past year and length of time taken, date of most recent review, and editor evaluation of submitted reviews. We often go beyond the RR reviewer database to identify scholars with expertise relevant to a particular manuscript. This can include reading through the article's bibliography to 
identify authors who have recently published in a similar area or by conducting a PubMed keyword search to identify experts in the field of the submitted paper. We also sometimes ask people we know in a relevant specialty whether they know of someone who would be appropriate.

Potential reviewers are contacted about their availability and interest in reviewing. Inquiries to reviewers are sent via RR automated E-mail messages, which include the manuscript abstract and the assignment deadline. When prospective reviewers agree to serve, they are permitted access to the manuscript and reviewing instructions. Reviewers send their critique back to the $7 A B F M$ using the RR system.

\section{The Editor's Decision}

Once a sufficient number of thoughtful reviews are obtained, the editor assigned to the manuscript makes a judgment that takes into consideration the critiques and recommendations from the peer reviewers, and other aspects such as relevance to the Fournal's niche, generalizability of findings, and usefulness to clinicians or researchers. We also take into account the number of manuscripts in the queue to be published as well as our impression that the paper can be suitably revised. Editors consult with one another as needed. Frequent reasons for rejection after peer review are based on an assess- ment that the paper doesn't provide enough new information, or if the message is too complex or too narrow. Common validity concerns include low response rates, unvalidated research instruments, and an unsuitable comparison group (or lack thereof). With few exceptions, the reviewers receive a copy of the decision letter sent to authors with all reviews appended.

\section{Why Peer Review for the JABFM?}

What motivates busy scholars, scientists, and clinicians to volunteer to spend the hours required to critically appraise the work of a stranger? Reviewers have many motivations, including the desire to advance research and practice, a commitment to nurture colleagues, personal professional development, reading up-to-date literature reviews, and professional recognition as expert in the field. Peer reviewing is an excellent activity to hone critical appraisal skills and also to improve manuscriptwriting skills. As a form of professional socialization, reviewers learn about the biomedical publishing process, and provide an important service to their profession.

\section{How to Peer Review}

In a future issue of the $7 A B F M$, we will discuss peer review ethics and how to write a useful peer review. 